\title{
Evaluating Economic Mobility under Opportunity Egalitarianism
}

\author{
Antonio Abatemarco ${ }^{1}$ \\ ${ }^{1}$ Department of Economics and Statistics, University of Salerno (I) and CELPE, Italy \\ Correspondence: Antonio Abatemarco, Department of Economics and Statistics, University of Salerno, Via \\ Giovanni Paolo II 132, Fisciano (SA), Italy. Tel: 39-089-962-277. E-mail: aabatemarco@ unisa.it
}

Received: November 9, 2017

Accepted: November 25, 2017 Online Published: November 30, 2017

doi:10.5539/ijef.v9n12p260

URL: https://doi.org/10.5539/ijef.v9n12p260

\begin{abstract}
While inter-generational income mobility is commonly understood to be socially desirable in that it promotes equality of life chances, social desirability of intra-generational income mobility is a much more controversial issue, which is known to be concerned with inequality and uncertainty effects, as well as aversion to income fluctuations. In this paper social welfare effects of intra-generational income mobility are investigated from the perspective of an opportunity egalitarian social planner. We show that, given the trade-off between inequality and uncertainty effects, social desirability of income mobility strongly depends on the characteristics of income switchings which are required to be rewarding the more deserving individuals and/or compensating the unluckier ones. In this sense, we suggest that egalitarianism of opportunity, more than aversion to intertemporal fluctuations, is crucial for motivating the optimality of empirically observed low degrees of income mobility as compared to perfect mobility processes (complete reversal).
\end{abstract}

Keywords: intra-generational mobility, inequality of opportunity, social welfare

\section{Introduction}

"Income mobility is relevant to several social issues, although in potentially conflicting ways ... On the one hand mobility may be viewed as a Good Thing because it is an indicator of how open society is and of the degree of equality of opportunity. Also, to some people, greater inequality at a point in time is more tolerable if accompanied by significant mobility: mobility smooths transitory variations in income so that permanent inequality is less than observed inequality. On the other hand, mobility may also be interpreted as a synonym for income fluctuations and thence economic insecurity, a Bad Thing." This extract from Jarvis and Jenkins (1998) is a very effective description of the different dimensions of social welfare influenced by income mobility.

In this paper social welfare effects of income mobility are investigated under the hypothesis of an opportunity egalitarian social planner. More precisely, we focus on intra-generational income mobility of the exchange kind, that is, on the effects of longitudinal (positional) income switchings over time.

The distinction between inter- and intra-generational mobility is crucial as the former captures the inter-generational transmission of inequality through the quantification of the incidence of origin income (father) on destination income (son), meanwhile the latter highlights the instability of individual income paths over time. Evidently, inter-generational income mobility - also known as social mobility - is one of the possible measures of equality of opportunity which is perfectly attained in the case of perfect origin independence (equality of life chances according to van de Gaer et al. (2011)). Intra-generational mobility, instead, is not immediately related with equality of opportunity, but it is commonly understood to characterize more meritocratic societies, e.g. with less rigidities in the labor market.

An additional distinction concerns the separation between exchange and structural mobility where the former refers to positional income switchings over time, while the latter concerns changes in the income distribution over time (Fields \& Ok, 1999). Exchange mobility is a micro phenomenon reflecting the instability of individual income positions which may be generated by intrinsic characteristics of an economy like labor market flexibility. Structural mobility, instead, captures macro aspects, i.e. the dynamics of income inequality and growth effects, that may be investigated independently of individual identities over time.

In the existing literature several contributions have investigated the social welfare effects of intra-generational exchange mobility (hereafter, income mobility). Within the ex-post utilitarian approach it has been observed that income mobility is socially desirable because the marginal utility of income at time $t+1$ can be fairly assumed to 
be decreasing with income at time t (Atkinson \& Bourguignon, 1982, Atkinson, 1983). The same conclusion is achieved within the the theory of outcome egalitarianism as income mobility allows to reduce permanent (multi-period) income inequality of outcomes (Shorrocks, 1980). More recently, doubts on the social desirability of income mobility have been advanced in Creedy and Wilhelm (2002), Gottschalk and Spolaore (2002), and Bibi et al. (2014). The former contribution shows that, given a specific mobility process with income at time $t+1$ being determined by a regression towards the mean and stochastic income movements, if individuals are averse to income fluctuations, then income mobility does not need to be social welfare improving (Note 1). The possibility for social undesirability of income mobility is confirmed in Bibi et al. (2014) without assuming any specific mobility process, but assuming iso-elastic preferences of both individuals and the social decision-maker. Here, in line with Creedy and Wilhelm (2002), aversion to both income fluctuations and income inequality is assumed (Note 2). Differently, Gottschalk and Spolaore (2002) emphasize the social welfare loss which may result from income mobility in the presence of risk aversion when an intertemporal perspective is considered in place of the traditional ex-post approach. As a result, three different effects of income mobility are considered simultaneously: permanent (multi-period) income inequality reduction, utility loss due to uncertainty and utility loss due to intertemporal income fluctuations (Note 3).

It is worth observing that the main literature arguing in favor of the possibility of social undesirability of income mobility strongly relies on 'aversion to income fluctuations'. This unobjectionable assumption is particularly relevant when evaluating social desirability of income mobility as it allows to exclude the equivocal solution by which maximum social welfare is achieved if and only if all individuals switch symmetrically their income positions (i.e. perfect mobility).

An ultimate but more controversial issue concerns the implications of (exchange) income mobility for productivity in the labor market. From Shapiro and Stiglitz (1984) wage (exchange) mobility is expected to be observed when the going wage is higher than the market wage (implying involuntary unemployment), meaning that the threat to be fired is effective against shirking (Note 4). In this sense, to the extent that wage mobility generates income mobility, an increase of income mobility is a Good Thing since it is expected to make the threat more effective and labor productivity higher, i.e. more effort rewarding. However, this must not be necessarily the case, because income mobility may be originating from factors beyond individual control (e.g. health endowment, bad luck), which would make income mobility rewarding circumstances independently of effort, that is a Bad Thing for any opportunity egalitarian. As such, income mobility cannot be said to be generally Good or Bad on a priori grounds, but it is definitely Just when compensating for unluckiness (i.e., increasing the incomes of unlucky poor individuals) and/or rewarding high-effort (i.e., increasing the incomes of high-effort poor individuals).

In this paper implications of income mobility on shirking are neglected (Note 5), but the perspective of an opportunity egalitarian planner is retained. More precisely, we investigate the impact of income mobility on social welfare in terms of uncertainty and inequality effect when the traditional approach of equality of outcomes is replaced by equality of opportunity (e.g., Sen, 1992; Roemer, 1998; Rawls, 2001; Roemer \& Trannoy, 2015) (Note 6). Specifically, we opt for Roemer's approach by which income inequalities are said to be legitimate when originating from responsible choices (principle of reward), while illegitimate when generated by circumstances, i.e. factors beyond individual control (principle of compensation).

In line with the existing literature we find that, depending on the size of aversion parameters, income mobility may be either socially desirable or undesirable. However, we wish to contribute to the ongoing debate by emphasizing that (i) social desirability of income mobility also depends on the opportunity/circumstance type (hereafter, $h$-type) and responsibility/effort type (hereafter, $e$-type) of 'movers', that is, an income switching may be desirable or undesirable depending on the benefit for the worse $h$-type and/or the better $e$-type, and (ii) the introduction of opportunity egalitarianism, even if in the absence of aversion to intertemporal income fluctuations, is sufficient to jeopardize the equivocal result of social welfare optimality under perfect mobility.

By virtue of the first result, it is shown that, if the perspective of an opportunity egalitarian social planner is embraced, then emphasis must be posed on the ability of the policy-maker to design the current mobility process in such a way as to reward effort or compensate for bad circumstances. The second result, instead, suggests an additional motivation for non-optimality of perfect mobility with respect to standard assumptions on aversion to intertemporal income fluctuations. Intuitively, as optimal mobility policies must account for the $h$-type and $e$-type of individuals, we argue that the relatively low (empirically observed) mobility as compared to perfect mobility is normatively justified by the impossibility (or incapacity) to implement additional income switchings which are Just from the perspective of an opportunity egalitarian social planner. 
The paper is organized as follows. In section 2, we discuss the basic model when distributive justice is defined as equality of outcomes. Here, the standard approach proposed in Gottschalk and Spolaore (2002) is reformulated in such a way as to highlight the inequality and the uncertainty effect. In section 3 inequality of outcomes is replaced by inequality of opportunity. The main implications of the different ethical value judgment are emphasized. Section 4 concludes.

\section{Income Mobility, Uncertainty and Equality of Outcomes}

Let's consider a population of $n$ income units whose income distributions at time $\mathrm{t}$ and $\mathrm{t}+1$ are, respectively, $x_{t}:=x_{1, t}, \ldots, x_{n, t}$ and $x_{t+1}:=x_{1, t+1}, \ldots, x_{n, t+1}$, with $x_{t}, x_{t+1} \in \Re_{++}^{n}$. For each income distribution, let's define $N$ income classes for each period. The standard Atkinson and Bourguignon's (1982) utilitarian social welfare function (hereafter, SWF) is

$$
W=\sum_{i=1}^{N} \sum_{j=1}^{N} u\left(x_{i}, x_{j}\right) \pi_{i j}
$$

where $x_{i}$ and $x_{j}$ indicate, respectively, the income level associated to the $i$-th income class at time $\mathrm{t}$, and the income level associated to the $j$-th income class at time $\mathrm{t}+1$, whereas $\pi_{i j}$ is the probability to belong to class $i$ at time $\mathrm{t}$ and class $j$ at time $\mathrm{t}+1$ (i.e., contingency table). Remarkably, to capture the sole exchange mobility, we focus exclusively on the case of income classes defined up to quantiles in each period, so that $\sum_{i=1}^{N} \pi_{i j}=$ $\sum_{j=1}^{N} \pi_{i j} \forall i, j$.

As shown in Atkinson and Bourguignon's (1982), given an increasing and concave utility function $u\left(x_{i}, x_{j}\right)$ with respect to incomes at time $t$ and $t+1$, social desirability of exchange mobility is determined by the sign of the second-order cross derivative $u_{i j}^{\prime \prime}(\cdot)$.

Notably, (1) can be equivalently rewritten as

$$
W=\sum_{i=1}^{N} \pi_{i} \sum_{j=1}^{N} \pi_{j \mid i} u\left(x_{i}, x_{j}\right)
$$

where $\pi_{i}=\sum_{j=1}^{N} \pi_{i j}$ indicates the share of income units belonging to the $\mathrm{i}$-th income class at time t, and $\pi_{j \mid i}$ is the probability of being in the $\mathrm{j}$-th income class at time $\mathrm{t}+1$ given the $\mathrm{i}$-th origin income class at time $\mathrm{t}$ (transition matrix).

This SWF is known to imply the equivalence between the degree of risk aversion and inequality aversion. Indeed, let's assume indifference to income fluctuations between time $t$ and time $t+1$ with a zero interest rate in the absence of credit market imperfections (e.g., Aaberge \& Mogstad, 2010; Bibi et al., 2014), by which $u\left(x_{i}, x_{j}\right)=$ $\psi\left(x_{i}+x_{j}\right)=\psi\left(y_{i j}\right)$ where $\psi(\cdot)$ is assumed to be continuously differentiable and monotone, whose first and second-order derivatives must be signed as $u(\cdot)$ 's ones by construction. As such, the SWF in (2) is equivalent to

$$
W=\sum_{i=1}^{N} \pi_{i} \psi\left(\tilde{y}_{i}\right)
$$

where $\tilde{y}_{i}=\psi^{-1}\left[\sum_{j=1}^{N} \pi_{j \mid i} \psi\left(y_{i j}\right)\right]$ is known as certainty equivalent income (Markowitz, 1952). To the extent that both risk and inequality aversion are determined by the concavity of the same function $\psi(\cdot)$, it must be the case that risk and inequality aversion coincide with each other. However, even if inequality and risk aversion are related concepts, still one may adduce several motivations to argue against equivalence. For instance, one may reasonably argue that risk aversion is determined at the individual level, whereas inequality aversion concerns the sphere of social preferences. Remarkably, this would offer a theoretical foundation to empirical evidences showing that risk aversion sensibly differ with respect to inequality aversion (e.g., Amiel et al., 1999; Carlsson et al., 2005; Ferrer-i-Carbonell \& Ramos, 2010) (Note 7).

In this paper, to escape from the equivalence above, we propose a generalization of the SWF in (3) by which risk and inequality aversion are allowed to differ to each other

$$
W=\sum_{i=1}^{N} \pi_{i} F\left[\sum_{j=1}^{N} \pi_{j \mid i} \psi\left(y_{i j}\right)\right]=\sum_{i=1}^{N} \pi_{i} \phi\left(\tilde{y}_{i}\right)
$$

where $F[\cdot]$ is any continuously differentiable and monotone transformation function such that $F[\psi(\cdot)]=\phi(\cdot)$ with $\phi^{\prime}(\cdot)>0$ and $\phi^{\prime \prime}(\cdot) \leq 0$.

Social welfare is intended as the expected utility of $N$ lotteries at time 0 , where each lottery is valued in terms of its corresponding certainty equivalent (multi-period) income. Specifically, each lottery consists of different possible multi-period incomes as defined in the presence of inter-temporal uncertainty generating from the mobility process.

As such, the separation between uncertainty and inequality aversion in the SWF may be reformulated in terms of 
Harsanyi's (1955) approach to utilitarianism; one may reasonably assume that the social decision-maker evaluates each lottery in terms of "personal" utility, meanwhile an "impersonal" utility function is required when assessing the expected utility of $N$ lotteries at time 0 . An immediate implication of this approach is that efficiency is considered ex-ante, i.e. it accounts for the impact of income uncertainty on individual welfare (Note 8).

Given the SWF in (4), we refer to the corresponding social evaluation function (hereafter, SEF), or abbreviated social welfare function (Lambert, 1993),

$$
V=\overline{\tilde{y}}(1-\tilde{I})
$$

where $\overline{\tilde{y}}$ and $\tilde{I}$ are, respectively, the mean and Atkinson's (1970) inequality index as calculated with respect to the distribution of certainty equivalent incomes (Note 9).

Given the virtual SEF function as obtained under the hypothesis of perfect immobility, $V^{*}=\overline{\tilde{y}}^{*}\left(1-\tilde{I}^{*}\right)$, it must be the case that

$$
V-V^{*}=\left[\overline{\tilde{y}}^{*}\left(\tilde{I}^{*}-\tilde{I}\right)\right]+\left[\left(\overline{\tilde{y}}-\overline{\tilde{y}}^{*}\right)\left(1-\tilde{I}^{*}\right)\right]
$$

where the first factor in square brackets is the inequality effect (Good Thing), that is, the welfare gain due to the compensation of income disparities in the multi-period income distribution due to exchange mobility. The second factor, instead, is the uncertainty effect (Bad Thing), that is, the welfare loss due to the concavity of $\psi($.$) ,$ i.e. risk aversion. Remarkably, in the presence of mobility the two effects are oppositely signed, and clearly dependent to each other in magnitude.

To highlight the trade-off between these two income mobility effects, let' $\mathrm{s}$ consider the simplest case of a transition matrix with two income classes identified by two income levels $\left(x_{1}, x_{2} \in \Re_{++}\right)$such that income (exchange) mobility can be identified by a single parameter $\delta$ (Note 10) i.e.

Table 1. Bistochastic transition matrix

$$
\left(\begin{array}{ll}
1-\delta & \delta \\
\delta & 1-\delta
\end{array}\right)
$$

Also, to avoid any sort of implication in terms of structural mobility or growth (e.g., Markandya, 1982; Ruiz-Castillo, 2004; Bourguignon, 2011), we assume fixed income levels over time, i.e., $x_{1, t}=x_{1, t+1}$ and $x_{2, t}=x_{2, t+1}$. This automatically implies $y_{12}=y_{21}$ and $y_{12}-y_{11}=y_{22}-y_{21}$ (Note 11).

As quantiles have been used at time $t$ and $t+1$, by construction, it must be the case that the $2 \times 2$ transition matrix is bi-stochastic, i.e., $\sum_{i=1}^{2} \pi_{j \mid i}=\sum_{j=1}^{2} \pi_{j \mid i}=1 \forall i, j$. Income mobility is absent (perfect immobility) when $\delta=0$, while it is maximum (perfect mobility) when $\delta=1$. In addition, when $\delta=0.5$ then the lottery associated to any individual is perfectly independent of the class of origin (perfect equality of opportunity in the case of intergenerational mobility). For all $\delta \in[0,0.5]$, the transition matrix is said to be monotone (Conlisk, $1990)$ as the lottery of the richer individuals always dominates the lottery of the poorer ones at time t. On the contrary, for all $\delta \in[0.5,1]$, the opposite occurs, so that poor individuals at time $\mathrm{t}$ face a better lottery than rich ones.

Given the opposite sign of the uncertainty and inequality effect, the implications of increasing mobility are established in the following Proposition where $\widetilde{K}$ stands for approximately $K$.

Proposition 2.1. Given empirically plausible degrees of risk aversion (Note 12), for all $\delta \in[0, \widetilde{0.5}]$, if income mobility increases then the uncertainty effect decreases (welfare loss), whereas the inequality effect increases (welfare gain). For all $\delta \in] \widetilde{0.5}, 1]$, the uncertainty and inequality effects are both increasing (welfare increasing).

Proof 2.1. See the appendix.

Proposition 2.1 is a simplified version of the more general case discussed in Gottschalk and Spolaore (2002). More precisely, to better emphasize the trade-off between uncertainty and inequality effects characterizing the SEF in (5) for all $\delta \in[0, \widetilde{0.5}]$, indifference to income fluctuations has been assumed (perfect credit markets). The following Corollary highlights a standard result of the theory of income mobility.

Corollary 2.1. In the presence of inequality and risk aversion but indifference to income fluctuations, social welfare is maximum under perfect mobility (i.e., $\delta=1$ ).

As empirically observed mobility in all countries is known to be far away from perfect mobility (i.e., complete 
reversal), usually closer to perfect immobility, Corollary 2.1 would leave room for two alternative options; either observed mobility is (somehow) optimal, in that societies are characterized by strong aversion to income fluctuations independently of risk aversion (Gottschalk \& Spolaore, 2002), or, astonishingly, aversion to income fluctuations is not so strong and observed mobility is far away from being welfare maximizing in modern societies. In this paper we offer a third alternative, that is implicit in opportunity egalitarianism, which makes the impact of aversion to income fluctuations more credible in supporting the optimality of far-from- perfect mobility processes, a point to which we shall return in the next section.

Recalling the definition of Atkinson's (1970) inequality index, given two income classes, the SEF in (5) can be rewritten as

$$
V=\left\{\begin{array}{l}
{\left[0.5\left(\tilde{y}_{1}\right)^{1-\varepsilon}+0.5\left(\tilde{y}_{2}\right)^{1-\varepsilon}\right]^{\frac{1}{1-\varepsilon}} \quad \forall \varepsilon \neq 1} \\
0.5 \log \tilde{y}_{1}+0.5 \log \tilde{y}_{2} \quad \varepsilon=1
\end{array}\right.
$$

where $\varepsilon>0$ measures aversion to inequality in the distribution of certainty equivalent incomes. Once again, it is worth observing that $\varepsilon$ is expected to capture the inequality aversion of the social-decision maker, not individuals.

Similarly, if the isoelastic utility function is assumed once again for aversion to uncertainty, then

$$
V=\left[0.5\left((1-\delta) y_{11}^{1-\lambda}+\delta y_{12}^{1-\lambda}\right)^{\frac{1-\varepsilon}{1-\lambda}}+0.5\left(\delta y_{21}^{1-\lambda}+(1-\delta) y_{22}^{1-\lambda}\right)^{\frac{1-\varepsilon}{1-\lambda}}\right]^{\frac{1}{1-\varepsilon}}
$$

where $\lambda>0$ is the degree of risk aversion. In contrast with $\varepsilon, \lambda$ is defined at the individual level and can be easily though as the average degree of aversion to uncertainty of individuals. As such, SEF in (8) is measured by a sort of 'equally distributed certainty equivalent income'.

Proposition 2.2. If $\varepsilon \geq \lambda$, then the inequality effect dominates the uncertainty effect for all $\delta$. If the uncertainty effect dominates the inequality effect, then $\delta \in[0, \widetilde{0.5}]$ and $\varepsilon<\lambda$.

Proof 2.2. See the appendix.

Remarkably, by Proposition 2.2 it is emphasized that, even if perfect mobility is welfare maximizing, in contrast with Atkinson and Bourguignon (1982) and Shorrocks (1978), an increase of exchange mobility does not need to be necessarily socially desirable. This result holds because income mobility generates two oppositely signed welfare effects, none of each is necessarily dominating the other for all possible values of $\delta$. In addition, Proposition 2.2 shows that the dominance of the one or the other effect, as one may expect, strongly depends on the relative magnitude of the degrees of aversion to inequality and uncertainty.

As special cases, if the social decision-maker is inequality neutral (i.e., $\varepsilon=0$ ), then the sole uncertainty effect survives so that mobility is socially undesirable for all $\delta \in[0, \widetilde{0.5}]$, while it is socially desirable for all $\delta \in[\widetilde{0.5}, 1]$. On the other side, if the society as a whole is uncertainty neutral (i.e., $\lambda=0$ ), then the sole inequality effect survives, so that mobility is generally socially desirable for all $\delta \in[0,1]$.

Considering that (i) the trade-off between uncertainty and inequality effects may make income mobility improvements socially undesirable when $\lambda>\varepsilon$ (necessary but not sufficient condition), and (ii) any increase of income mobility is socially desirable for all $\delta \in[\widetilde{0.5}, 1]$, if $\frac{\partial V}{\partial \delta}$ is negative for some $\delta$, then there must exist some $\delta^{*} \in[0, \widetilde{0.5}]$ which, at least locally, minimizes social welfare. This is immediately relevant for the design of optimal policies, as an improvement of income mobility may be socially desirable or undesirable depending on the initial degree of income mobility. In addition, further policy implications may be inferred by considering the major determinants of $\delta^{*}$.

Proposition 2.3. If there exists $\delta^{*} \in[0, \widetilde{0.5}]$ which minimizes social welfare, then (i) $\delta^{*}$ is unique, and (ii) $\delta^{*}$ is increasing with inequality in the one-period income distribution for all plausible empirically observed values of income inequality (i.e., Gini $>1 / 6$ ), $\lambda$, and $\varepsilon$ (i.e., $\forall \lambda>\varepsilon$ with $\lambda>2$ ) (Note 13).

Proof 2.3. See the appendix.

Basically, any increase of income mobility generates (i) a social benefit in terms of inequality, (ii) a benefit for the poorest part of the population whose income expectations are improved, and (iii) a cost for the richest part of the population whose income expectations become worse. Thus, if risk aversion is stronger than inequality aversion (which is usually the case), and if there exists $\delta^{*} \in[0, \widetilde{0.5}]$, then for all $\delta<\delta^{*}$ an increase of income 
mobility is welfare decreasing because (iii) is dominating. On the contrary, for all $\delta>\delta^{*}$, the overall benefit of mobility, in terms of multi-period inequality compensation over time, plus the benefit for currently poor individuals, is more than compensating the welfare loss due to worsening income expectations for the richest part of the population.

Remarkably, $\delta^{*} \in[0, \widetilde{0.5}]$ is immediately affected by one-period income inequality; any increase in one-period inequality makes individual lotteries more and more risky, so that, to the extent that the population is more risk averse than inequality averse, $\delta^{*}$ increases. As such, it must be the case that the higher is one-period inequality, the larger is the interval of $\delta^{*}$ such that an increase of income mobility is welfare reducing (Note 14).

\section{Income Mobility, Uncertainty and Equality of Opportunity}

Let's now consider social welfare effects of income mobility from the prospective of an opportunity egalitarian social planner. In the case of equality of opportunity income disparities are intended as compensation deserving whenever originating from different circumstances, i.e. factors beyond individual control. On the contrary, income disparities are said to be legitimate, and not compensation deserving, when determined by different responsible choices (e.g., Arneson, 1989; Dworkin, 1981a, 1981b; Fleurbaey, 1995; Roemer, 1998). Specifically, as it has been widely emphasized in the empirical literature (Bourguignon et al., 2007; Checchi et al., 2008; Ferreira \& Gignoux, 2011) (Note 15), responsible choices may be partially influenced by circumstances, so that, to distinguish between legitimate and illegitimate disparities, both the direct and indirect effect of circumstances must be accounted for. In this sense, income inequalities originating from different responsible choices due to heterogenous circumstances are to be regarded as illegitimate as well.

To the extent that some pairwise inequalities may be regarded as legitimate from the perspective of an opportunity egalitarian, the set of social welfare improving rich-to-poor transfers is inevitably restricted as compared to outcome egalitarianism. As such, recalling income mobility effects from the previous section, the inequality effect is expected to be mitigated, in that the compensation of income inequalities over time is now said to be socially desirable if and only if it is rewarding responsible choices and/or compensating for worse circumstances.

In this paper we consider the following social welfare function

$$
W=\sum_{h=1}^{H} \pi^{h} G\left\{\sum_{e=1}^{E} \pi^{e \mid h} \sum_{i=1}^{N} \pi_{i}^{h e} F\left[\sum_{j=1}^{N} \pi_{j \mid i}^{h e} \psi\left(y_{i j}\right)\right]\right\}
$$

where $\pi^{h}$ is the share of income units belonging to the $h$-th opportunity type (or $h$-type), $\pi^{e \mid h}$ is the probability of being of the $e$-th responsibility type (or $e$-type) as conditioned to the $h$-type, $\pi_{i}^{h e}$ is the probability of being in the $i$-th income class at time $\mathrm{t}$ for an individual of the $h$-type and $e$-type (hereafter, $\{h, e\}$-profile), $\pi_{j \mid i}^{h e}$ is the probability of being in class $j$ at time $t+1$ as conditioned to the $i$-th origin income class for a $\{h, e\}$-profile, and $G[$.$] is the increasing and concave function aggregating social welfare levels associated$ to subgroups differing from each other with respect to the $h$-type.

Even if a pure axiomatization of the opportunity egalitarian SWF is beyond the scope of this paper (e.g., Peragine, 2004; Fleurbaey \& Maniquet, 2006), three main aspects need to be emphasized.

First, since SWF in (9) is defined as a concave aggregation of social welfare levels associated to each $h$-type, our approach extends van de Gaer's (1993) definition to a multi-period framework (Note 16). This means that, in line with the principle of utilitarian reward, the social decision-maker is averse to social welfare disparities among subgroups of different $h$-types, but neutral with respect to social welfare disparities originating from different $e$-types (but same $h$-type).

Second, to the extent that incomes within each $\{h, e\}$-profile may differ to each other, (9) implements a non-dichotomic approach to equality of opportunity (e.g., Lefranc et al., 2009) where a distinction is made between circumstances and luck. More precisely, according to Lefranc et al. (2009), a separating line is drawn between circumstances and luck (non-dichotomic approach), because " $[a]$ ssuming that society has agreed on a given set of circumstances does not imply that the remaining determinants will reflect individual responsible choice and should be treated as effort". In this sense, different aversion parameters are conceived for inequalities originating from circumstances, which are often discriminating, and those originating from luck, which are not.

Third, social welfare in (9) is maximum when redistributive policies are designed in such a way as to equalize social welfare for different $h$-types, independently of the impact of circumstances on responsible choices, i.e., the social decision-maker is assumed to promote equal social welfare among different $h$-types even if better $h$-types may correspond, on average, to better $e$-types (indirect effect of heterogenous circumstances). 
As compared to the definition of social welfare in the previous section (4), it is worth observing that (9) differs (i) for the neutrality of income disparities between individuals with different $e$-types (but same $h$-type), and (ii) for the differentiation of aversion parameters to be applied to within-profile income inequalities (non-discriminatory) and between h-types (discriminatory) social welfare disparities.

Formally, let's assume that complete orderings among $h$-types and $e$-types exist. A separating line is drawn between local and global contingency tables, where the former contingency tables $\pi_{i j}^{h e}$ indicate the share of individuals belonging to the $\{h, e\}$-profile with income $x_{i}$ at time $\mathrm{t}$ and $x_{j}$ at time $\mathrm{t}+1$, i.e., one single local contingency table is associated to each $\{h, e\}$-profile. The global contingency table $\pi_{i j}$, instead, indicates the share of individuals with income $x_{i}$ at time $\mathrm{t}$ and $x_{j}$ at time $\mathrm{t}+1$, independently of the $\{h, e\}$-profile and, like in the previous section, income classes are assumed to be defined up to quantiles both at time $t$ and $t+1$.

Let $\pi_{j \mid i}^{h e}$ be the local transition matrix for the $\{h, e\}$-profile which is stochastic for each row (not bistochastic). Recalling the SWF definition in (4), (9) can be rewritten as

$$
W=\sum_{h=1}^{H} \pi^{h} G\left[\sum_{e=1}^{E} \pi^{e \mid h} \sum_{i=1}^{N} \pi_{i}^{h e} \phi\left(\tilde{y}_{i h e}\right)\right]
$$

where $\tilde{y}_{i h e}$ is the certainty equivalent income for an individual with the $i$-th origin income and $\{h, e\}$-profile.

Once again, by recalling the definition of 'equally distributed certainty equivalent income' in (8), let's define the expected social welfare for individuals with the same $h$-type as $\overline{\tilde{y}}_{h}=\left[\sum_{e=1}^{E} \pi^{e \mid h} V_{h e}\right]$. Then, (10) can be rewritten as $W=\sum_{h=1}^{H} \pi^{h} G\left(\overline{\tilde{y}}_{h}\right)$, and the corresponding SEF is

$$
V=\mu(1-I)
$$

where $\mu$ and $I$ indicate, respectively, the expected social welfare among different $h$-types and the size of inequality in the distribution of social welfare among $h$-types (Note 17).

Once again, given the virtual SEF function as obtained under the hypothesis of perfect immobility, $V^{*}=\overline{\tilde{\mu}}^{*}(1-$ $\left.I^{*}\right)$, it must be the case that

$$
V-V^{*}=\left[\mu^{*}\left(I^{*}-I\right)\right]+\left[\left(\mu-\mu^{*}\right)\left(1-I^{*}\right)\right]
$$

where the first and second factor in square brackets capture the inequality and uncertainty effect respectively.

As before, in the presence of mobility the two effects are oppositely signed, and clearly dependent to each other in magnitude. However, as compared to the corresponding function in the case of equality of outcomes (5), the latter is defined up to an aggregation of states of the world instead of individuals. This allows to capture the sole effect of income disparities determined by differing circumstances.

Let's consider the simplest case of a population of two income classes, identified by two income levels $\left(x_{1}\right.$ and $x_{2}$ ), whose global contingency table $\pi_{i j}$ is constructed by using quantiles both at time $t$ and $t+1$, so that the transition matrix for the whole population appears like in Table 1 (bistochastic). In addition, let's assume that two different $h$-types and $e$-types exist in the population, respectively, $h:=1,2$ and $e:=1,2$. The four corresponding (not bistochastic) transition matrices $\pi_{j \mid i}^{\text {he }}$ are reported in Table 2,

Table 2. Local (stochastic) transition matrices

$$
\begin{array}{ll}
\left(\begin{array}{ll}
1-\delta_{11} & \delta_{11} \\
\theta_{11} & 1-\theta_{11}
\end{array}\right) & \left(\begin{array}{ll}
1-\delta_{21} & \delta_{21} \\
\theta_{21} & 1-\theta_{21}
\end{array}\right) \\
\left(\begin{array}{ll}
1-\delta_{12} & \delta_{12} \\
\theta_{12} & 1-\theta_{12}
\end{array}\right) & \left(\begin{array}{ll}
1-\delta_{22} & \delta_{22} \\
\theta_{22} & 1-\theta_{22}
\end{array}\right)
\end{array}
$$

where, by construction, it must be $\sum_{h=1}^{2} \sum_{e=1}^{2} \pi_{1}^{h e} \delta_{h e}=\sum_{h=1}^{2} \sum_{e=1}^{2} \pi_{2}^{h e} \theta_{h e}$ with $\pi_{i}^{h e}$ indicating the share of individuals of the $h$-type and $e$-type belonging to the $i$-th income class at time t.

By recalling the 'equally distributed certainty equivalent income' in (8) and by introducing an additional isoelastic aggregation function for $G[\cdot],(11)$ becomes 


$$
\begin{aligned}
& V=\left\{\pi ^ { 1 } \left[\pi^{1 \mid 1}\left(\pi_{1}^{11}\left(y_{11}^{1-\lambda}\left(1-\delta_{11}\right)+y_{12}^{1-\lambda} \delta_{11}\right)^{\frac{1-\varepsilon}{1-\lambda}}+\pi_{2}^{11}\left(y_{22}^{1-\lambda}\left(1-\theta_{11}\right)+y_{21}^{1-\lambda} \theta_{11}\right)^{\frac{1-\varepsilon}{1-\lambda}}\right)^{\frac{1}{1-\varepsilon}}+\right.\right. \\
&\left.\pi^{2 \mid 1}\left(\pi_{1}^{12}\left(y_{11}^{1-\lambda}\left(1-\delta_{12}\right)+y_{12}^{1-\lambda} \delta_{12}\right)^{\frac{1-\varepsilon}{1-\lambda}}+\pi_{2}^{12}\left(y_{22}^{1-\lambda}\left(1-\theta_{12}\right)+y_{21}^{1-\lambda} \theta_{12}\right)^{\frac{1-\varepsilon}{1-\lambda}}\right)^{\frac{1}{1-\varepsilon}}\right]^{1-\gamma}+ \\
& \pi^{2}\left[\pi^{1 \mid 2}\left(\pi_{1}^{21}\left(y_{11}^{1-\lambda}\left(1-\delta_{21}\right)+y_{12}^{1-\lambda} \delta_{21}\right)^{\frac{1-\varepsilon}{1-\lambda}}+\pi_{2}^{21}\left(y_{22}^{1-\lambda}\left(1-\theta_{21}\right)+y_{21}^{1-\lambda} \theta_{21}\right)^{\frac{1-\varepsilon}{1-\lambda}}\right)^{\frac{1}{1-\varepsilon}}+\right. \\
&\left.\left.\pi^{2 \mid 2}\left(\pi_{1}^{12}\left(y_{11}^{1-\lambda}\left(1-\delta_{22}\right)+y_{12}^{1-\lambda} \delta_{22}\right)^{\frac{1-\varepsilon}{1-\lambda}}+\pi_{2}^{22}\left(y_{22}^{1-\lambda}\left(1-\theta_{22}\right)+y_{21}^{1-\lambda} \theta_{22}\right)^{\frac{1-\varepsilon}{1-\lambda}}\right)^{\frac{1}{1-\varepsilon}}\right]^{1-\gamma}\right\}^{\frac{1}{1-\gamma}}
\end{aligned}
$$

where $\gamma>0$ indicates the degree of aversion to inequality with respect to the distribution of social welfare among $h$-types, i.e. aversion to opportunity inequality as defined for our purposes.

Given this simplified framework, the effects of income mobility can be analyzed by considering the effects of changes in $\delta$ and $\theta$. More precisely, to focus on the sole mobility of the exchange kind a separating line has to be drawn among within- and between-profiles income switchings. In the former case an increase of exchange mobility implies a positional switching over time between a rich and a poor income unit belonging to the same $\{h, e\}$-profile, that is, a rich income unit at time t becoming poor at the next stage and a poor income unit at time $\mathrm{t}$ becoming rich at $\mathrm{t}+1$. As a result, both $\delta_{h e}$ and $\theta_{h e}$ vary as a result of exchange mobility. In the case of between-profiles income switchings, this involves two individuals differing with respect to the $h$-type, or $e$-type, or even both. As a result, changes in $\delta_{h e}$ and $\theta_{h e}$ occur simultaneously in different local transition matrices.

Proposition 3.1. (Within-profile exchange mobility) If exchange mobility occurs within the same $\{h, e\}$-profile, then the inequality effect dominates the uncertainty effect $\forall \varepsilon \geq \lambda$. If the uncertainty effect dominates the inequality effect, then $\delta \in[0,0.5]$ and $\varepsilon<\lambda$.

Proof 3.1 See the appendix.

Thus, as one may expect for within-profile mobility, social desirability is independent of $\gamma$, and gives similar results as in the case of equality of outcomes with two major highlights (straightforward from proof 3.1).

Corollary 3.1. An increase of within-profile exchange income mobility can be socially desirable in some profiles, meanwhile socially undesirable in some others.

This is immediately relevant for policy purposes, because income mobility may sensibly differ depending on $h$ and $e$-types, e.g., less-educated individuals and blacks are known to be characterized by more instability in their earnings than those who are more highly educated and non-black (Gittleman \& Joyce, 1996).

Corollary 3.2. The social welfare effect of within-profile exchange mobility is stronger (positive or negative) whenever income switchings occur in poorer $\{h, e\}$-profiles (Note 18).

As one may expect, according to Corollary 3.2, the social decision-maker may reasonably concentrate on mobility enhancing policies for poor profiles when the inequality effect is the dominating one, while the opposite should be supported when the uncertainty effect prevails.

When considering the case of between-profiles exchange mobility, two further specifications are required depending on (i) profiles affected by the income switching, and (ii) the profile that is benefitting from mobility (i.e., a poor income unit at time $\mathrm{t}$ becoming rich at $\mathrm{t}+1$ ). As such, three categories of exchange mobility processes can be identified: (i) the income switching interests profiles with the same $h$-type, e.g. $\{1,1\}$ and $\{1,2\}$, or (ii) profiles with different $e$-types, e.g. $\{1,1\}$ and $\{2,1\}$, or (iii) profiles with differing $h$-types and $e$-types, e.g. $\{1,1\}$ and $\{2,2\}$. For our purposes, we focus on the former two cases, as the latter is inevitably determined by some combination of the previous ones. In turn, for each of the three categories above, two different scenarios may occur. For the first category, (a) a poor individual at time t may become rich at time $t+1$ in the profile with the worse e-type (i.e. $\delta_{h 1}$ increases), meanwhile a rich individual at time t becomes poor at $\mathrm{t}+1$ in the better $e$-type profile (i.e. $\theta_{h 2}$ increases), or (b) a poor individual at time t may become rich at time $t+1$ in the profile with the better $e$-type (i.e. $\delta_{h 2}$ increases), meanwhile a rich individual at time t becomes poor at $\mathrm{t}+1$ in the worse $e$-type profile (i.e. $\theta_{h 1}$ increases). Remarkably, in (a) the exchange mobility process is benefitting worse $e$-types, whereas the opposite occurs in case (b).

Definition 3.1. (e-type positive dependence) The income distribution and the mobility process are said to be positively dependent of the e-type if (i) $\pi_{1}^{h 1} \geq \pi_{1}^{h 2}$ and (ii) $\delta_{h 2} \geq \delta_{h 1}, \theta_{h 2} \leq \theta_{h 1}$ with at least one inequality 
holding strictly.

Basically, in the case of ' $e$-type positive dependence' the income generation process is positively influenced by the $e$-type both at time $\mathrm{t}$ and from time t to time $\mathrm{t}+1$, so that, better $e$-types correspond to better income distributions at time t, and better $e$-types are predominantly benefitting of the mobility process.

Proposition 3.2. (Between-profiles (within $\boldsymbol{h}$-type) exchange mobility) For exchange income mobility occurring between different profiles of the same h-type, if (i) $\varepsilon \geq \lambda$, (ii) the individual with better e-type is the one benefitting of the income switching, (iii) e-type positive dependence holds, and (iv) $\pi^{2 \mid h}>\pi^{1 \mid h}$, then the inequality effect dominates the uncertainty effect.

Proof 3.2. See the appendix.

First, as compared to Proposition 2.2, it must be the case that when moving from outcomes to opportunity egalitarianism, $\varepsilon \geq \lambda$ is not sufficient any longer to make income mobility socially desirable. Intuitively, as the set of illegitimate pairwise income disparities is smaller than under egalitarianism of outcomes, the inequality effect of income mobility is downgraded, i.e., income switchings may equalize legitimate income disparities (e.g., case (a) above). As a result, it can be shown that a welfare minimizing degree of mobility $\left(\delta^{*}\right)$ in the global transition matrix may now exist for $\delta \in[0,0.5]$ even if $\varepsilon \geq \lambda$.

A second issue from Proposition 3.2 concerns the role of the $e$-type (i.e. conditions (ii) and (iii)). As one may expect, mobility enhancing policies are more likely to be socially desirable when prizing (incentivizing) effort. In addition, the more the $e$-type positively influences the income generation process, the more income mobility is socially desirable.

Third, from Proposition 3.2 it turns out that, under the hypothesis of $e$-type positive dependence, income mobility is more likely to be socially desirable when, within the same $h$-type, the profile that is benefitting from the mobility process is composed by a larger share of individuals. In this sense, if the hypothesis of fixed (exogenous) $e$-types were relaxed within a dynamic setting, one may reasonably expect that exchange mobility incentivizes $e$-types improvements which, in turn, enhance the positive social welfare effects of exchange mobility (Note 19).

Let's turn to the case of between-profiles income switchings within the same $e$-type, where the degree of aversion to opportunity inequality $(\gamma)$ is now expected to be relevant.

Definition 3.2. ( $h$-type positive dependence) The income distribution and the mobility process are said to be positively dependent of the $h$-type if (i) $\pi_{2}^{2 e} \geq \pi_{2}^{1 e}$, and (ii) $\delta_{2 e} \geq \delta_{1 e}, \theta_{2 e} \leq \theta_{1 e}$ with at least one inequality holding strictly.

Basically, in the case of $h$-type positive dependence, it is said, any improvement of the $h$-type is expected to increase both income and the probability to move upward in the income distribution over time.

Proposition 3.3. (Between-profiles (within $e$-type) exchange mobility) For exchange income mobility occurring between different profiles of the same e-type, if (i) exchange mobility benefits the profile with worse h-type, i.e., a poor individual at time t becomes rich at $t+1$ in profile $\{1, e\}$, meanwhile a rich individual at time $t$ becomes poor at $t+1$ in profile $\{2, e\}$, (ii) $\gamma \geq \varepsilon \geq \lambda$, (iii) h-type positive dependence holds, and (iv) $\frac{\pi^{1 e}}{\pi^{2 e}} \geq\left(\frac{\tilde{y}_{2 e}}{\tilde{y}_{1 e}}\right)^{\varepsilon}$ where $\tilde{y}_{h e}$ is social welfare in profile $\{h, e\}$, then the inequality effect dominates the uncertainty effect.

Proof 3.3. See the appendix.

Condition (i) highlights that, as compared to the case of outcome egalitarianism, to be socially desirable exchange mobility is additionally required to occur in the 'right direction', that is, it must compensate income disparities due to different circumstances.

In addition, as compared to Proposition 3.2, sufficient conditions are now more demanding, as more effects are at stake simultaneously: inequality of outcomes is reducing within two profiles, uncertainty is likely to be increasing across two profiles (as transition matrices are usually monotone), inequality of opportunity between $h$-types is reducing. It turns out that an increase of income mobility is more likely to be socially desirable when aversion to both within-profile income inequalities $(\varepsilon)$ and between $h$-types social welfare disparities $(\gamma)$ is stronger than risk aversion $(\lambda)$, which is not consistent with empirical findings.

In addition, as an income switching between two profiles with the same $e$-type but differing $h$-type improves 
social welfare in profile $\{1, e\}$ while reducing social welfare in profile $\{2, e\}$, condition (iv) ensures that the former effect is overwhelming $\left(\pi_{1 e}>>\pi_{2 e}\right)$, whereas condition $\gamma \geq \varepsilon$ ensures that overall social welfare, as obtained from the concave aggregation of social welfare levels associated to the two $h$-types, is increased. In this sense, any increase of between-profile income mobility is more likely to be socially desirable when the share of individuals with worse $h$-type is higher (Note 20).

The following Corollary is straightforward from proof of Proposition 3.3.

Corollary 3.3. Under h-type positive dependence, the social desirability of exchange mobility is greater when aversion to opportunity inequality is higher.

One of the immediate implications of the introduction of an opportunity egalitarian perspective is that exchange mobility is less likely to be socially desirable with respect to outcome egalitarianism. As we said above, this result occurs because aversion to income inequalities is now restricted to the sole within-profile disparities and, indirectly, to income disparities between-profiles with the same $e$-type. However, the higher is aversion to opportunity inequality, the more exchange mobility is likely to be socially desirable because it makes the inequality effect stronger as compared to the uncertainty effect.

An additional immediate implications of the introduction of an opportunity egalitarian perspective concerns the identification of the optimal size of exchange mobility (social welfare maximizing), to be compared with the result obtained under outcome egalitarianism in the previous section (see Corollary 2.1).

Proposition 3.4. (Bad exchange mobility) If (i) h-type and e-type positive dependence hold, (ii) $\pi^{2 \mid 2} \geq \pi^{2 \mid 1}$, and (iii) $\gamma \rightarrow+\infty$, then increasing exchange mobility by penalizing the individual with worse h-type is social welfare reducing for all $\delta_{\text {he }}, \theta_{\text {he }}$.

Proof 3.4. See the appendix.

Corollary 3.4 Overall perfect mobility (global transition matrix) is not necessarily welfare maximizing.

The latter result, which is an immediate implication of Proposition 3.4, is crucial; it emphasizes that, even if indifference to intertemporal income fluctuations is assumed, perfect mobility (i.e., complete reversal) is not necessarily welfare maximizing like in the previous section. This is due to the fact that some income switchings may not be socially desirable under opportunity egalitarianism. More precisely, to get perfect mobility in the overall transition matrix it must be the case that this result is achieved for each of the transition matrices associated to $\{h, e\}$-profiles. However, as Proposition 3.4 shows, given such a condition, it may still be possible to improve social welfare by dropping an income switching that is penalizing the worse $h$-type, that is, perfect mobility may not be social welfare maximizing. Notice that this is true for all $\delta_{h e}, \theta_{h e}$ satisfying conditions in Proposition 3.4, i.e. $\delta_{h e}, \theta_{\text {he }}>0.5$ included.

In other words, overall perfect mobility is still welfare maximizing when income mobility involves income units belonging to the same $h$-type only. Unfortunately, as exchange mobility is often driven by circumstances and effort variables, it turns out that this option is very unlikely to occur and, as a result, maximum social welfare is not expected to be achieved in the case of overall perfect mobility any longer. As such, recalling Corollary 2.1, we suggest that egalitarianism of opportunity may sensibly contribute to motivate the optimality of empirically observed low degrees of income mobility.

\section{Concluding Remarks}

Social welfare theory strongly relies on the trade-off between efficiency and equity. Income mobility is immediately relevant fior this trade-off as it generates implications in terms of both (ex-ante) efficiency and equity. First, if efficiency is defined in terms of expected utility, income mobility affects the value of lotteries in the presence of standard assumptions on risk aversion. Second, inequality in the one-period income distribution may be more tolerable in the presence of high income mobility, as income disparities tend to compensate to each other over time (Note 21).

In this paper the trade-off between uncertainty and inequality effects has been initially investigated under the hypothesis of an outcome egalitarian social planner. In this respect, it has been shown that, even if perfect mobility is expected to maximize social welfare, mobility enhancing policies may not be socially desirable at the margin whenever risk aversion is relatively higher than inequality aversion.

At the second stage, social welfare effects of income mobility have been considered under the hypothesis of an opportunity egalitarian social planner. As observed in section 1, the latter approach better than others allows to account for the expected relationship between meritocracy and income mobility. Here, three major results have been highlighted. First, it has been shown that income mobility is expected to be less socially desirable than 
under outcome egalitarianism as it may compensate legitimate income disparities over time (e.g. due to effort variables). Second, once the distinction between legitimate and illegitimate income disparities has been introduced, mobility cannot be said to be socially desirable or undesirable on a priori grounds, i.e. social desirability of income mobility strongly depends on the ability of the policy-maker to design mobility enhancing policies rewarding effort and compensating for bad circumstances. Finally, it is shown that in the presence of an opportunity egalitarian social planner perfect mobility is not expected to be social welfare maximizing any longer, that is, even if individuals are assumed to be neutral to intertemporal income fluctuations, the maximum reduction of two-period inequality (with zero costs in terms of uncertainty) may not be welfare maximizing. More precisely, if all income positions switch to each other in the society (perfect mobility) but most of the switchings occur in the 'wrong direction', i.e. rewarding circumstances and compensating for different effort, then there must exist a mobility reducing policy that is welfare improving. In this sense, one may argue that the relatively low mobility (with respect to perfect mobility), as empirically observed from real economies, is additionally justified by the impossibility (or incapacity) to switch all income positions ensuring, at the same time, a reward for better $e$-types and/or a compensation for worse $h$-types.

\section{References}

Aaberge, R., \& Mogstad, M. (2010). On the measurement of long-term income inequality and income mobility. IZA Discussion Papers, 4699. http://dx.doi.org/10.2139/ssrn.1417892

Aaberge, R., Mogstad, M., \& Peragine V. (2011). Measuring long-term inequality of opportunity. Journal of Public Economics, 95(3-4), 193-204. http://dx.doi.org/10.1016/j.jpubeco.2010.11.023

Abatemarco, A. (2015). A Gini approach to inequality of opportunity: Evidence from PSID. Empirical Economics, 49(4), 1497-1519. https://doi.org/10.1007/s00181-015-0918-y

Amiel, Y., Creedy, J., \& Hurn, S. (1999). Measuring Attitudes Towards Inequality. Scandinavian Journal of Economics, 101, 83-96. http://dx.doi.org/10.1111/1467-9442.00142

Arneson, R. J. (1989). Equality and equality of opportunity for welfare. Philosophical Studies, 56, 77-93. https://doi.org/10.1007/BF00646210

Arneson, R. J. (1999). Equality of opportunity for welfare defended and recanted. Journal of Political Philosophy, 7(4), 488-497. http://dx.doi.org/10.1111/1467-9760.00088

Atkinson, A. B. (1970). On the measurement of economic inequality. Journal of Economic Theory, 2(3), 244-263. https://doi.org/10.1016/0022-0531(70)90039-6

Atkinson, A. B. (1983). The Measurement of Economic Mobility. Social Justice and Public Policy, MIT Press, Cambridge, MA.

Atkinson, A. B., \& Bourguignon, F. (1982). The Comparison of Multi-Dimensioned Distributions of Economic Status. Review of Economic Studies, 49, 183-201. https://doi.org/10.2307/2297269

Bibi, S., Duclos, \& J.-Y. Araar, A. (2014). Mobility, taxation and welfare. Social Choice and Welfare, 42, 503-527. https://doi.org/10.1007/s00355-013-0749-8

Boland, P., \& Proschan, F. (1988). Multivariate arrangement increasing functions with application in probability and statistics, Journal of Multivariate Analysis, 25, 286-298. https://doi.org/10.1016/0047-259X(88)90052-8

Bourguignon, F. (2011). Non-anonymous growth incidence curves, income mobility and social welfare dominance. Journal of Economic Inequality, 9, 605-627. https://doi.org/10.1007/s10888-010-9159-7

Bourguignon, F., Ferreira, F. H. G., \& Menéndez, M. (2007). Inequality of opportunity in Brazil. Review of Income and Wealth, 53, 585-618. http://dx.doi.org/10.1111/j.1475-4991.2007.00247.x

Burkhauser, R. V., Nolan, B., \& Couch, K. A. (2011). Intragenerational Inequality and Intertemporal Mobility. In B. Nolan, W. Salverda, \& T. A. Smeeding (Eds.), The Oxford Handbook of Economic Inequality. Oxford University Press. https://doi.org/10.1093/oxfordhb/9780199606061.013.0021

Calo-Blanco, A., \& Garca-Peréz, J. (2014). On the welfare loss caused by inequality of opportunity. Journal of Economic Inequality, 12(2), 221-237. https://doi.org/10.1007/s10888-013-9247-6

Carlsson, F., Daruvala, D., \& Johansson-Stenman, O. (2005). Are People Inequality-Averse, or Just Risk-Averse? Economica, 72, 375-396. http://dx.doi.org/10.1111/j.0013-0427.2005.00421

Checchi, D., Peragine, V., \& Serlenga, L. (2008). Income inequality and opportunity inequality in Europe. 
Rivista di Politica Economica, 98, 263-292.

Conlisk, J. (1990). Monotone mobility matrices. Journal of Mathematical Sociology, 15, $173-191$. https://doi.org/10.1080/0022250X.1990.9990068

Creedy, J., \&Wilhelm, M. (2002). Income mobility, inequality and social welfare. Australian Economic Papers, 41, 140-150. http://dx.doi.org/10.1111/1467-8454.00155

Dardanoni, V. (1993). Measuring social mobility. Journal of Economic Theory, 61, $372-394$. https://doi.org/10.1006/jeth.1993.1073

Dworkin, R. (1981a). What is equality. Part 1: Equality of welfare. Philosophy and Public Affairs, 10, $185-246$.

Dworkin, R. (1981b). What is equality. Part 2: Equality of ressources. Philosophy and Public Affairs, 10, 283-345.

Ferreira, F. H. G., \& Gignoux, J. (2011). The measurement of inequality of opportunity: Theory and an application to Latin America. Review of Income and Wealth, 57, 622-657. http://dx.doi.org/10.1111/j.1475-4991.2011.00467.x

Ferrer-i-Carbonell, A., \& Ramos, X. (2010). Inequality Aversion and Risk Attitudes. IZA DP Series (No. 4703).

Fields, G. S., \& Ok, E. A. (1999). The measurement of income mobility: An introduction to the literature. In J. Silber (Ed.), Handbook on income inequality measurement (pp. 557-596). Norwell, MA: Kluwer Academic Publishers. https://doi.org/10.1007/978-94-011-4413-1_20

Fleurbaey, M. (1995). Equality and responsibility. European Economic Review, 39, $683-689$. https://doi.org/10.1016/0014-2921(94)00075-B

Fleurbaey, M. (2001). Egalitarian opportunities. Law and Philosophy, 20, $499-530$. https://doi.org/10.1023/A:1017589614382

Fleurbaey, M., \& Maniquet, F. (2006). Compensation and responsibility. In K. Arrow, A. Sen, \& K. Suzumura (Eds.), Handbook of Social Choice and Welfare. Elsevier, New York.

Friedman, M. (1962). Capitalism and Freedom. University of Chicago Press.

Gittleman, M., \& Joyce, M. (1996). Earnings Mobility and Long-Run Inequality: An Analysis Using Matched CPS Data. Industrial Relations, 35(2), 145-298. https://doi.org/10.1111/j.1468-232X.1996.tb00401.x

Gottschalk, P., \& Spolaore, E. (2002). On the Evaluation of Economic Mobility. Review of Economic Studies, 69, 191-208. https://doi.org/10.1111/1467-937X.00203

Hammond, P. (1983). Ex-post optimality as a dynamically consistent objective for collective choice under uncertainty. In P. K. Pattanaik, \& M. Salles (Eds.), Social Choice and Welfare. North-Holland. https://doi.org/10.1016/B978-0-444-86487-1.50017-4

Harris, R. (1978). Ex-post efficiency and resource allocation under uncertainty. Review of Economic Studies, 45, 427-436. https://doi.org/10.2307/2297245

Harsanyi, J. C. (1955). Cardinal welfare, individualistic ethics, and interpersonal comparisons of utility. Journal of Political Economy, 63(4), 309-321. https://doi.org/10.1086/257678

Jarvis, S., \& Jenkins, S. (1998). How much income mobility is there in Britain? Economic Journal, 108, $428-443$. http://dx.doi.org/10.1111/1468-0297.00296

Kranich, L. (1996). Equitable opportunities: An axiomatic approach. Journal of Economic Theory, 71, $131-147$. https://doi.org/10.1006/jeth.1996.0112

Lambert, P. J. (1993). The Distribution and Redistribution of Income: A Mathematical Analysis. Manchester University Press.

Lefranc, A., Pistolesi, N., \& Trannoy, A. (2009). Equality of opportunity and luck: Definitions and testable conditions. Journal of Public Economics, 93, 1189-1207. https://doi.org/10.1016/j.jpubeco.2009.07.008

Markandya, A. (1982). Intergenerational exchange mobility and economic welfare. European Economic Review, 17, 307-324. https://doi.org/10.1016/S0014-2921(82)80066-4

Markowitz, H. (1952). Portfolio selection. Journal of Finance, 7, 77-91. http://dx.doi.org/10.1111/j.1540-6261.1952.tb01525.x

Niehues, J., \& Peichl, A. (2014). Upper bounds of inequality of opportunity: theory and evidence for Germany 
and the US. Social Choice and Welfare, 43(1), 73-99. https://doi.org/10.1007/s00355-013-0770-y

Ok, E. (1997). On opportunity inequality measurement. Journal of Economic Theory, 77, 300-329. https://doi.org/10.1006/jeth.1997.2336

Palmisano, F. (2011). Mobility and long-term equality of opportunity. In J. G. Rodríguez (Ed.), Inequality of Opportunity: Theory and Measurement (Research on Economic Inequality, Vol. 19, pp. 51-75). https://doi.org/10.1108/S1049-2585(2011)0000019006

Peragine, V. (2004). Ranking income distributions according to equality of opportunity. Journal of Economic Inequality, 2, 11-30. https://doi.org/10.1023/B:JOEI.0000028404.17138.1e

Pirtillä, J., \& Uusitalo, R. (2010). A 'Leaky Bucket' in the Real World: Estimating Inequality Aversion using Survey Data. Economica, 77, 60-76. http://dx.doi.org/10.1111/j.1468-0335.2008.00729.x

Ramos, X., \& Van de gaer, D. (2016). Approaches to inequality of opportunity: Principles, measures, and evidence. Journal of Economic Syrveys, 30, 855-883. http://dx.doi.org/10.1111/joes.12121

Rawls, J. (2001). Justice as fairness: A restatement. Cambridge: Harward University Press.

Roemer, J. E. (1993). A pragmatic theory of responsibility for the egalitarian planner. Philosophy and Public Affairs, 22, 146-166.

Roemer, J. E. (1998). Equality of Opportunity. Cambridge, MA: Harvard University Press.

Roemer, J. E., \& Trannoy, A. (2015). Equality of Opportunity. In A. B. Atkinson, \& F. Bourguignon (Eds.), Handbook of Income Distribution (Vol. 2, pp. 217-300). https://doi.org/10.1016/B978-0-444-59428-0.00005-9

Ruiz-Castillo, X. (2004). The measurement of structural and exchange income mobility. Journal of Economic Inequality, 2, 219-228. https://doi.org/10.1007/s10888-004-4075-3

Salas, R., \& Rabadan I. (1998). Lifetime and Vertical Intertemporal Inequality, Income Smoothing, and Redistribution: A Social Welfare Approach. Review of Income and Wealth, 44(1), 63-79. http://dx.doi.org/10.1111/j.1475-4991.1998.tb00252.x

Sen, A. (1992). Inequality reexamined. Cambridge: Harward University Press.

Shapiro, C., \& Stiglitz, J. E. (1984). Equilibrium Unemployment as a Worker Discipline Device. American Economic Review, 74, 433-444.

Shorrocks, A. (1978). Income Inequality and Income Mobility. Journal of Economic Theory, 19, 376-393. https://doi.org/10.1016/0022-0531(78)90101-1

Van de Gaer, D. (1993). Equality of opportunity and investment in human capital. Ph.D. thesis, K.U. Leuven (1993).

Van de Gaer, D., Shokkaert, E., \& Martinez, M. (2001). Three meanings of inter-generational mobility. Economica, 68, 519-537. http://dx.doi.org/10.1111/1468-0335.d01-15

Villar, A. (2005). On the welfare evaluation of income and opportunity. Contributions to Theoretical Economics, 5(1). https://doi.org/10.2202/1534-5971.1129

\section{Notes}

Note 1. In addition, Creedy and Wilhelm (2002) show that income mobility may offset the negative effect of rising inequality under stringent conditions which are determined by the magnitude of aversion parameters (inequality and fluctuations).

Note 2. Bibi et al. (2014) also investigate the impact of taxation on the social welfare effects of income mobility.

Note 3. The magnitude of aversion parameters is shown to determine social (un)desirability of income mobility. In particular, the conditions under which origin independence is welfare maximizing are identified.

Note 4. If the going wage is the market wage, then more job mobility is expected because the threat to be fired is ineffective. However, this would not imply more income mobility as workers are re-hired immediately at the same market wage.

Note 5. Labor productivity improvements may generate price effects in the medium-term, which would be immediately relevant for multi-period social welfare as defined in terms of the unweighted aggregation of 
indirect utility functions (Atkinson, 1983). As such, to the extent that individual effort is assumed to be independent of income (wage) mobility, the analysis is developed under the hypothesis of fixed prices.

Note 6. Equality of opportunity has been investigated both from a theoretical (e.g., Kranich, 1996; Ok, 1997; Fleurbaey, 2001; Peragine, 2004) and empirical perspective (e.g., Bourguignon et al., 2007; Lefranc et al., 2009; Ferreira \& Gignoux, 2011; Niehues \& Peichl, 2014).

Note 7. While existing evidences on the degree of risk aversion usually agree on a coefficient of risk aversion between 2 and 3, results for the estimation of the coefficient of inequality aversion are much more controversial (e.g., Pirtillä \& Uusitalo, 2010). In Carlsson et al. (2005) the degree of inequality aversion is found between 1 and 2, while values between 0 and 1 are obtained in Amiel et al. (1999).

Note 8. For other approaches to social welfare under uncertainty see Harris (1978), Hammond (1983), and Dardanoni (1993).

Note 9. For an example of inequality aversion with respect to multi-period incomes see, among all, Salas and Rabadan (1998).

Note 10. All of the results reported in this paper can be generalized for the case of a bistochastic $n \times n$ transition matrix by identifying positive variations of income mobility with correlation increasing majorizations (Boland \& Proschan, 1988).

Note 11. The latter assumption is not required for our results but it allows to focus on the sole exchange mobility implications.

Note 12. See endnote 9.

Note 13. See endnote 9.

Note 14. This result may allow for additional insights if compared with existing empirical evidences showing that the two phenomena are usually found to be uncorrelated across countries. For a review on this literature see Burkhauser et al. (2011).

Note 15. For a review on the empirical literature see Ramos and Van de gaer (2012) and Abatemarco (2015).

Note 16. Van de Gaer (1993) defines social welfare as a concave aggregation of average outcomes associated to each $h$-type. Similarly, we propose a concave aggregation of social welfare levels associated to each $h$-type, where the outcomes of individuals with the same $\{h, e\}$-profile are not necessarily the same (non-dichotomic approach). In addition, to account for the uncertainty and inequality effect of income mobility, in our framework subgroup social welfare is defined in terms of the 'equally distributed certainty equivalent income'.

Note 17. For the application of the social evaluation function to capture the welfare loss due to inequality of opportunity see Villar (2005) and Calo-Blanco and Garca-Peréz (2014).

Note 18. Intuitively, if the inequality effect is overwhelming the uncertainty effect, then, since the welfare gain due to less inequality over-compensates the welfare loss due to worsening of the lottery faced by richer individuals - with the latter under-compensated by the improvement of the lottery faced by poorer ones - it must be the case that the higher is the proportion of poorer individuals the more within-profile exchange mobility is socially desirable. Conversely, when the uncertainty effect is the dominating one, then an increase in the proportion of poorer individuals makes the uncertainty effect even more dominating, so that within-profile exchange mobility is more socially undesirable.

Note 19. Obviously, the opposite would occur in the presence of negative dependence from the $e$-type.

Note 20. For the analysis of the implications of intra-generational mobility between $h$-types in terms of long-term inequality (not social welfare) see Aaberge et al. (2011) and Palmisano (2011).

Note 21. "Consider two societies that have the same distribution of annual income. In one there is great mobility and change so that the position of particular families in the income hierarchy varies widely from year to year. In the other, there is great rigidity so that each family stays in the same position year after year. Clearly, in any meaningful sense, the second would be the more unequal society" (Friedman, 1962).

\section{Appendix}

A) Proof of Proposition 2.1. As exchange mobility implies a rich-to-poor transfer in terms of two-period income, then inequality $(\tilde{I})$ must be decreasing for all $\delta \in[0,1]$, so that 


$$
\frac{\partial\left[\tilde{y}^{*}\left(\tilde{I}^{*}-\tilde{I}\right)\right]}{\partial \delta}>0 \quad \forall \delta \in[0,1]
$$

For the uncertainty effect, let $\tilde{y}_{1}<\tilde{y}_{2}$ be the certainty equivalent incomes for the poor and rich income unit at time $t$ respectively. Indicating by $S\{\cdot\}$ the sign of the expression, it can be shown that

$$
S\left\{\frac{\partial\left[\left(\overline{\tilde{y}}-\overline{\tilde{y}}^{*}\right)\left(1-\tilde{I}^{*}\right)\right]}{\partial \delta}\right\}=S\left\{\frac{\partial \tilde{y}_{1}}{\partial \delta}+\frac{\partial \tilde{y}_{2}}{\partial \delta}\right\}
$$

where

$$
\frac{\partial \tilde{y}_{1}}{\partial \delta}+\frac{\partial \tilde{y}_{2}}{\partial \delta}=\frac{1}{1-\lambda}\left[\left((1-\delta) y_{11}^{1-\lambda}+\delta y_{12}^{1-\lambda}\right)^{\frac{\lambda}{1-\lambda}}\left(-y_{11}^{1-\lambda}+y_{12}^{1-\lambda}\right)+\left(\delta y_{21}^{1-\lambda}+(1-\delta) y_{22}^{1-\lambda}\right)^{\frac{\lambda}{1-\lambda}}\left(y_{21}^{1-\lambda}-y_{22}^{1-\lambda}\right)\right]
$$

whose sign is not uniquely defined for all $\delta \in[0,1]$. More specifically, recalling $y_{12}=y_{21}=1 / 2\left(y_{11}+y_{22}\right)$ and given $k>1: y_{22}=k y_{11}$, for $\delta=0$

$$
\frac{\partial \tilde{y}_{1}}{\partial \delta}+\left.\frac{\partial \tilde{y}_{2}}{\partial \delta}\right|_{\delta=0}=\frac{1}{1-\lambda} y_{11}^{\lambda}(1+k)^{1-\lambda}\left[2^{\lambda-1}\left(1+k^{\lambda}\right)-(1+k)^{\lambda}\right]
$$

which is zero for $k=1$ and $\lambda=2$. In addition, as the factor in square brackets is strictly increasing in both $k$ and $\lambda$ for $k=1$ and $\lambda=2$, it must be the case that (17) is negative for all $\lambda>2$, meaning that, for $\delta=0$ the welfare loss of the rich group originating from increasing mobility is overwhelming the welfare gain of the poor group. On the contrary, by easy algebraic computations it can be shown that the right-hand side of (16) is strictly positive for $\delta=1$. Finally, by taking the first-order condition, there must exist $\left.\delta^{*} \in\right] 0,1\left[:\left(\frac{\partial \tilde{y}_{1}}{\partial \delta}+\frac{\partial \tilde{y}_{2}}{\partial \delta}\right)=0\right.$, where

$$
\delta^{*}=-\frac{\left(1-k^{\lambda-1}(\vartheta)^{-1+\frac{1}{\lambda}}\right)}{\left(2^{\lambda-1} k^{\lambda-1}(1+k)^{1-\lambda}-1\right)\left(1+(\vartheta)^{\frac{1}{\lambda}}\right)}
$$

with $\vartheta=\frac{-2^{\lambda}(1+k)^{-\lambda+1}+2}{2^{\lambda}(1+k)^{-\lambda+1}-2 k^{1-\lambda}}$. Remarkably, by simulation, $\delta^{*}$ can be shown to approximate $\delta=0.5$ for all $\lambda>2$. Indeed, from (16) it must be the case that

$$
\left.S\left\{\frac{\partial \tilde{y}_{1}}{\partial \delta}+\frac{\partial \tilde{y}_{2}}{\partial \delta}\right\}\right|_{\delta=0.5}=S\left\{(1-\lambda)^{-1}\left[(1+k)^{2-2 \lambda}-\left(1+k^{2-2 \lambda}\right)\right]\right\}
$$

which for $\lambda>2$ is clearly negligible. This proves that for all $\delta \in[0, \widetilde{0.5}]$ any increase of $\delta$ generates an increase of $\tilde{y}_{1}$ while reducing $\tilde{y}_{2}$ where the latter effect is dominating. On the contrary, for all $\delta \in[\widetilde{0.5}, 1]$ the opposite occurs, so that the uncertainty effect (negative) is increasing.

B) Proof of Proposition 2.2. From Proposition 2.1, if the inequality effect is dominating, then $\frac{\partial V}{\partial \delta}>0$, and vice versa. From eq. (8)

$$
\begin{aligned}
\frac{\partial V}{\partial \delta}= & \frac{1}{1-\lambda}\left[0.5\left((1-\delta) y_{11}^{1-\lambda}+\delta y_{12}^{1-\lambda}\right)^{\frac{\varepsilon-1}{\lambda-1}}+0.5\left((1-\delta) y_{22}^{1-\lambda}+\delta y_{21}^{1-\lambda}\right)^{\frac{\varepsilon-1}{\lambda-1}}\right]^{\frac{\varepsilon}{1-\varepsilon}} \\
& {\left[0.5\left(-y_{11}^{1-\lambda}+y_{12}^{1-\lambda}\right)\left((1-\delta) y_{11}^{1-\lambda}+\delta y_{12}^{1-\lambda}\right)^{\frac{\varepsilon-\lambda}{\lambda-1}}+0.5\left(-y_{22}^{1-\lambda}+y_{21}^{1-\lambda}\right)\left((1-\delta) y_{22}^{1-\lambda}+\delta y_{21}^{1-\lambda}\right)^{\frac{\varepsilon-\lambda}{\lambda-1}}\right] }
\end{aligned}
$$

where, neglecting the always positive first term in brackets, it must be the case that for all $\varepsilon \geq \lambda$ (20) is positive for all $\delta \in[0,1]$, whatever $\varepsilon \lesseqgtr 1$ and $\lambda \lesseqgtr 1$. As such, the inequality effect is dominating, and social welfare increasing. To prove the second part of the Proposition, first notice that $\frac{\partial V}{\partial \delta}$ can be negative; e.g., if $\lambda=10$, $\varepsilon=0.5, y_{11}=2, y_{12}=y_{21}=10, y_{22}=18$, and $\delta=0$, then it can be computationally shown that $\frac{\partial V}{\partial \delta}<0$. Second, from proposition 2.1 it must be the case that $(20)$ is positive for all $\delta \in[\widetilde{0.5}, 1]$. As such, recalling the 
first part of the proof, it must be the case that if the uncertainty effect is dominating, then $\varepsilon<\lambda$ and $\delta \in[0, \widetilde{0.5}]$. C) Proof of Proposition 2.3. Given $y_{12}=y_{21}=1 / 2\left(y_{11}+y_{22}\right)$ by construction, let define $k>2: y_{22}=k y_{11}$. Recalling $y_{11}=2 x_{1, t}$ and $y_{22}=2 x_{2, t}$, it must be the case that $k$ captures inequality in the one period income distribution ( $k>2 \Leftrightarrow \operatorname{Gini}>1 / 6)$. From eq. (20), by solving the first-order condition $\frac{\partial V}{\partial \delta}=0$, it must be the case that if there exists $\delta^{*} \in[0, \widetilde{0.5}]$ then it is unique with

$$
\begin{aligned}
\delta^{*}= & {\left[y_{22}^{1-\lambda}\left(y_{22}^{1-\lambda}-2^{-1+\lambda}\left(y_{11}+y_{22}\right)^{1-\lambda}\right)^{\frac{\lambda-1}{\varepsilon-\lambda}}-y_{11}^{1-\lambda}\left(-y_{11}^{1-\lambda}+2^{-1+\lambda}\left(y_{11}+y_{22}\right)^{1-\lambda}\right)^{\frac{\lambda-1}{\varepsilon-\lambda}}\right] / } \\
& {\left[y_{22}^{1-\lambda}\left(y_{22}^{1-\lambda}-2^{-1+\lambda}\left(y_{11}+y_{22}\right)^{1-\lambda}\right)^{\frac{\lambda-1}{\varepsilon-\lambda}}-2^{-1+\lambda}\left(y_{11}+y_{22}\right)^{1-\lambda} y_{22}^{1-\lambda}\left(y_{22}^{1-\lambda}-2^{-1+\lambda}\left(y_{11}+y_{22}\right)^{1-\lambda}\right)^{\frac{\lambda-1}{\varepsilon-\lambda}}+\right.} \\
& \left.-y_{11}^{1-\lambda}\left(y_{11}^{1-\lambda}+2^{-1+\lambda}\left(y_{11}+y_{22}\right)^{1-\lambda}\right)^{\frac{\lambda-1}{\varepsilon-\lambda}}+2^{-1+\lambda}\left(y_{11}+y_{22}\right)^{1-\lambda} y_{11}^{1-\lambda}\left(y_{11}^{1-\lambda}+2^{-1+\lambda}\left(y_{11}+y_{22}\right)^{1-\lambda}\right)^{\frac{\lambda-1}{\varepsilon-\lambda}}\right]
\end{aligned}
$$

which, by recalling $y_{22}=k y_{11}$, simplifies to

$$
\delta^{*}=\left[1+2^{\lambda-1}\left(\frac{(1-\vartheta) k^{\lambda-1}}{\left(\vartheta k^{\lambda-1}-1\right)(1+k)^{\lambda-1}}\right)\right]^{-1}
$$

with $\vartheta=\left(\frac{2 k^{1-\lambda}-2^{\lambda}(1+k)^{1-\lambda}}{-2+2^{\lambda}(1+k)^{1-\lambda}}\right)^{(-1+\lambda) /(-\varepsilon+\lambda)}$. Specifically, given $\lambda>\varepsilon$ and $\lambda>1$ it must be the case that if $\exists \delta^{*} \in[0,0.5]$, then $\vartheta \in\left[k^{1-\lambda}, 1\right]$ (otherwise $\delta^{*}>1$ ) with $\partial \vartheta / \partial k<0$, and $\vartheta=0$ for $k \rightarrow+\infty$ and $\vartheta \rightarrow 1^{-}$ for $k \rightarrow 1^{+}$. To prove the Proposition we show that $\left(\frac{(1-\vartheta) k^{\lambda-1}}{\left(\vartheta k^{\lambda-1}-1\right)(1+k)^{\lambda-1}}\right)$ is decreasing with respect to $k$, so that $\partial \delta^{*} / \partial k>0$ must hold. To simplify algebraic computations, notice that if $\left(\frac{(1-\vartheta) k^{\lambda-1}}{\left(\vartheta k^{\lambda-1}-1\right)(1+k)^{\lambda-1}}\right)$ is decreasing with respect to $k$, then it must be equivalently the case that

$$
\frac{(1-\vartheta) k^{\lambda-1}+\left(\partial\left((1-\vartheta) k^{\lambda-1}\right) / \partial k\right)}{\left(\vartheta k^{\lambda-1}-1\right)(1+k)^{\lambda-1}+\left(\partial\left(\left(\vartheta k^{\lambda-1}-1\right)(1+k)^{\lambda-1}\right) / \partial k\right)}<\frac{(1-\vartheta) k^{\lambda-1}}{\left(\vartheta k^{\lambda-1}-1\right)(1+k)^{\lambda-1}}
$$

which simplifies to

$$
(2-\lambda)(-1+\vartheta)-\frac{\partial \vartheta}{\partial k} k^{\lambda-1}<\vartheta(\lambda-2)(1-\vartheta) k^{\lambda-1}+\vartheta(1-\vartheta)(\lambda-1) k^{\lambda}
$$

where each of the four factors is positive for all $\lambda>2$ and $\vartheta \in\left[k^{1-\lambda}, 1\right]$. Recalling that $\left(\vartheta k^{\lambda-1}-1\right)>0$ is a necessary condition for $\delta^{*}$ to exist, it must be the case that the first term on the right-hand side is strictly larger than the first term on the left-hand side. As such, to prove the proposition, it is sufficient to show that

$$
-\frac{\partial \vartheta}{\partial k} k^{\lambda-1}<\vartheta(1-\vartheta)(\lambda-1) k^{\lambda}
$$

The latter is generally satisfied in our interval of interest. Under the worst scenario (i.e., $\lambda=2$ and $k=2$ ) the right-hand side is $\vartheta(1-\vartheta)(\lambda-1) k^{\lambda}=1$ whereas the left-hand side is positive but lower than one. In addition, the left-hand side is strictly increasing with respect to $k$, so that (25) holds for all $k>2$.

D) Proof of Proposition 3.1. Within-profile exchange mobility implies $\theta_{h e}=\frac{\pi_{1}^{h e}}{\pi_{2}^{h e}} \delta_{h e} \forall\{h, e\}$, that is, any increase of mobility generates a positive variation of both $\delta_{h e}$ and $\theta_{h e}$ which preserves at time $\mathrm{t}+1$ the income distribution at time t. By replacing $\theta_{h e}=\frac{\pi_{1}^{h e}}{\pi_{2}^{h e}} \delta_{h e} \forall\{h, e\}$ in (13) and considering, for instance, an income switching in profile $\{1,1\}$,

$$
\begin{aligned}
& \operatorname{Sign}\left\{\frac{\partial V}{\partial \delta_{11}}\right\}=\operatorname{Sign}\left\{\frac { \pi _ { 1 } ^ { 1 1 } \pi ^ { 1 | 1 } } { 1 - \lambda } \left[\left(-y_{11}^{1-\lambda}+y_{12}^{1-\lambda}\right)\left(y_{11}^{1-\lambda}\left(1-\delta_{11}\right)+y_{12}^{1-\lambda} \delta_{11}\right)^{\frac{\varepsilon-\lambda}{-1+\lambda}}+\right.\right. \\
& \left.\left.+\left(-y_{22}^{1-\lambda}+y_{21}^{1-\lambda}\right)\left(y_{22}^{1-\lambda}\left(-1+\theta_{11}\right)+y_{21}^{1-\lambda} \theta_{11}\right)^{\frac{\varepsilon-\lambda}{-1+\lambda}}\right]\right\}
\end{aligned}
$$

where, given $y_{12}=y_{21}$, if $\lambda \leq \varepsilon$, then $\frac{\partial V}{\partial \delta_{11}}>0$ whatever $\lambda \lesseqgtr 1$ and $\varepsilon \lesseqgtr 1$. If $\lambda>\varepsilon$, whatever $\lambda \mid 1$, then 
the sign of $\frac{\partial V}{\partial \delta_{11}}$ is undefined for $\delta_{11} \in[0,0.5]$. The second part of Proposition 3.1 is straightforward from proofs of Proposition 2.1 and Proposition 2.2, which apply equivalently to the case of within-profile income mobility. As such, for $\delta_{11} \in[0.5,1]$, it must be the case that both the uncertainty and inequality effects are welfare improving, i.e. $\frac{\partial V}{\partial \delta_{11}}>0$.

E) Proof of Proposition 3.2. Let's assume that the rich income unit in $\{1,1\}$ becomes poor at time $t+1$ by switching with a poor income unit in $\{1,2\}$ becoming rich at time $t+1$, then this implies an increase in both $\delta_{12}$ and $\theta_{11}$. Also, as the global transition matrix is bistochastic, it must be the case that

$$
\theta_{11}=\frac{\pi_{1}^{11} \delta_{11}+\pi_{1}^{12} \delta_{12}+\pi_{1}^{21} \delta_{21}+\pi_{1}^{22} \delta_{22}-\pi_{2}^{12} \theta_{12}-\pi_{2}^{21} \theta_{21}-\pi_{2}^{22} \theta_{22}}{\pi_{2}^{11}}
$$

By replacing the latter in (13), deriving by $\delta_{12}$, and re-arranging, it must be

$$
\begin{aligned}
& \operatorname{Sign}\left\{\frac{\partial V}{\partial \delta_{12}}\right\}=\operatorname{Sign}\left\{\frac { 1 } { \lambda - 1 } \left\{\left[\left(y_{22}^{1-\lambda}-y_{21}^{1-\lambda}\right)\left[y_{21}^{1-\lambda} \theta_{11}+y_{22}^{1-\lambda}\left(1-\theta_{11}\right)\right]^{\frac{\varepsilon-\lambda}{\lambda-1}}\right.\right.\right. \\
& \left.\left[\left(y_{11}^{1-\lambda}\left(1-\delta_{11}\right)+y_{12}^{1-\lambda} \delta_{11}\right)^{\frac{\varepsilon-1}{\lambda-1}} \pi_{1}^{11}+\left(y_{21}^{1-\lambda} \theta_{11}+y_{22}^{1-\lambda}\left(1-\theta_{11}\right)\right)^{\frac{\varepsilon-1}{\lambda-1}} \pi_{2}^{11}\right]^{\frac{\varepsilon}{1-\varepsilon}} \pi^{1 \mid 1}\right]+ \\
& {\left[\left(y_{11}^{1-\lambda}-y_{12}^{1-\lambda}\right)\left[y_{12}^{1-\lambda} \delta_{12}+y_{11}^{1-\lambda}\left(1-\delta_{12}\right)\right]^{\frac{\varepsilon-\lambda}{\lambda-1}}\right.} \\
& \left.\left.\left.\left[\left(y_{11}^{1-\lambda}\left(1-\delta_{12}\right)+y_{12}^{1-\lambda} \delta_{12}\right)^{\frac{\varepsilon-1}{\lambda-1}} \pi_{1}^{12}+\left(y_{21}^{1-\lambda} \theta_{12}+y_{22}^{1-\lambda}\left(1-\theta_{12}\right)\right)^{\frac{\varepsilon-1}{\lambda-1}} \pi_{2}^{12}\right]^{\frac{\varepsilon}{1-\varepsilon}} \pi^{2 \mid 1}\right]\right\}\right\}
\end{aligned}
$$

where $\frac{\partial V}{\partial \delta_{12}}>0$ if (i) $\lambda \leq \varepsilon$ for all $\lambda \mid 1, \varepsilon_{\mid}^{\mid} 1$, (ii) $\delta_{12}>\delta_{11}, \theta_{12}<\theta_{11}, \pi_{1}^{11}>\pi_{1}^{12}$, and (iii) $\pi^{2 \mid 1}>\pi^{1 \mid 1}$.

F) Proof of Proposition 3.3. Let's assume that the poor income unit in profile $\{1,1\}$ becomes rich at $t+1$ by switching her position with a rich income unit in profile $\{2,1\}$ becoming poor at $t+1$, then this implies that both $\delta_{11}$ and $\theta_{21}$ increase. Also, as the global transition matrix is bistochastic, it must be the case that

$$
\theta_{21}=\frac{\pi_{1}^{11} \delta_{11}+\pi_{1}^{12} \delta_{12}+\pi_{1}^{21} \delta_{21}+\pi_{1}^{22} \delta_{22}-\pi_{2}^{11} \theta_{11}-\pi_{2}^{12} \theta_{12}-\pi_{2}^{22} \theta_{22}}{\pi_{2}^{21}}
$$

By replacing the latter in (13), deriving by $\delta_{11}$, and re-arranging, it must be

$$
\begin{aligned}
& \operatorname{Sign}\left\{\frac{\partial V}{\partial \delta_{11}}\right\}=\operatorname{Sign}\left\{\frac { \pi _ { 1 } ^ { 1 1 } } { 1 - \lambda } \left\{\left(y_{12}^{1-\lambda}-y_{11}^{1-\lambda}\right)\left[y_{12}^{1-\lambda} \delta_{11}+y_{11}^{1-\lambda}\left(1-\delta_{11}\right)\right]^{\frac{\varepsilon-\lambda}{\lambda-1}}\right.\right. \\
& {\left[\left[y_{12}^{1-\lambda} \delta_{11}+y_{11}^{1-\lambda}\left(1-\delta_{11}\right)\right]^{\frac{\varepsilon-1}{\lambda-1}} \pi_{1}^{11}+\left[y_{21}^{1-\lambda} \theta_{11}+y_{22}^{1-\lambda}\left(1-\theta_{11}\right)\right]^{\frac{\varepsilon-1}{\lambda-1}} \pi_{2}^{11}\right]^{\frac{\varepsilon}{1-\varepsilon}} \pi^{1 \mid 1}} \\
& {\left[\left[\left[y_{12}^{1-\lambda} \delta_{11}+y_{11}^{1-\lambda}\left(1-\delta_{11}\right)\right]^{\frac{\varepsilon-1}{\lambda-1}} \pi_{1}^{11}+\left[y_{21}^{1-\lambda} \theta_{11}+y_{22}^{1-\lambda}\left(1-\theta_{11}\right)\right]^{\frac{\varepsilon-1}{\lambda-1}} \pi_{2}^{11}\right]^{\frac{1}{1-\varepsilon}} \pi^{1 \mid 1}+\right.} \\
& \left.\left.+\left[\left[y_{12}^{1-\lambda} \delta_{12}+y_{11}^{1-\lambda}\left(1-\delta_{12}\right)\right]^{\frac{\varepsilon-1}{\lambda-1}} \pi_{1}^{12}+\left[y_{21}^{1-\lambda} \theta_{12}+y_{22}^{1-\lambda}\left(1-\theta_{12}\right)\right]^{\frac{\varepsilon-1}{\lambda-1}} \pi_{2}^{12}\right]^{\frac{1}{1-\varepsilon}} \pi^{2 \mid 1}\right]^{-\gamma} \pi^{1}\right\}+ \\
& -\frac{\pi_{1}^{11}}{1-\lambda}\left\{\left(y_{22}^{1-\lambda}-y_{21}^{1-\lambda}\right)\left[y_{21}^{1-\lambda} \theta_{21}+y_{22}^{1-\lambda}\left(1-\theta_{21}\right)\right]^{\frac{\varepsilon-\lambda}{\lambda-1}}\right. \\
& {\left[\left[y_{12}^{1-\lambda} \delta_{21}+y_{11}^{1-\lambda}\left(1-\delta_{21}\right)\right]^{\frac{\varepsilon-1}{\lambda-1}} \pi_{1}^{21}+\left[y_{21}^{1-\lambda} \theta_{21}+y_{22}^{1-\lambda}\left(1-\theta_{21}\right)\right]^{\frac{\varepsilon-1}{\lambda-1}} \pi_{2}^{21}\right]^{\frac{\varepsilon}{1-\varepsilon}} \pi^{1 \mid 2}} \\
& {\left[\left[\left[y_{12}^{1-\lambda} \delta_{21}+y_{11}^{1-\lambda}\left(1-\delta_{21}\right)\right]^{\frac{\varepsilon-1}{\lambda-1}} \pi_{1}^{21}+\left[y_{21}^{1-\lambda} \theta_{21}+y_{22}^{1-\lambda}\left(1-\theta_{21}\right)\right]^{\frac{\varepsilon-1}{\lambda-1}} \pi_{2}^{21}\right]^{\frac{1}{1-\varepsilon}} \pi^{1 \mid 2}+\right.} \\
& \left.\left.\left.+\left[\left[y_{12}^{1-\lambda} \delta_{22}+y_{11}^{1-\lambda}\left(1-\delta_{22}\right)\right]^{\frac{\varepsilon-1}{\lambda-1}} \pi_{1}^{22}+\left[y_{21}^{1-\lambda} \theta_{22}+y_{22}^{1-\lambda}\left(1-\theta_{22}\right)\right]^{\frac{\varepsilon-1}{\lambda-1}} \pi_{2}^{22}\right]^{\frac{1}{1-\varepsilon}} \pi^{2 \mid 2}\right]^{-\gamma} \pi^{2}\right\}\right\}
\end{aligned}
$$

where the factor on the second (resp. sixth) line is social welfare in profile $\{1,1\}$, i.e. $\tilde{y}_{11}$ (resp. profile $\{2,1\}$ and $\tilde{y}_{21}$ ) to the power of $\varepsilon$ multiplied by $\pi^{1 \mid 1}$ (resp. $\pi^{1 \mid 2}$ ). Also, the factor in square brackets on the third and 
fourth lines (resp. seventh and eighth) is the average social welfare for individuals with $h$-type $\{1\}$, i.e. $\overline{\tilde{y}}_{1}$ (resp. $h$-type $\{2\}$ and $\overline{\tilde{y}}_{2}$ ) to the power of $-\gamma$ multiplied by $\pi^{1}$ (resp. $\pi^{2}$ ). Given $\varepsilon>\lambda$, condition (i) ensures that the first line is positive and larger than the fourth one. Lines from two to four and lines from five to eight can be rewritten, respectively, as $\tilde{\tilde{y}}_{11}^{\varepsilon} \pi^{1 \mid 1} \overline{\tilde{y}}_{1}^{-\gamma} \pi^{1}$ and $\tilde{\tilde{y}}_{21}^{\varepsilon} \pi^{1 \mid 2} \overline{\tilde{y}}_{2}^{-\gamma} \pi^{2}$, by which the former is larger than the latter if

$$
\left(\frac{\tilde{y}_{11}}{\tilde{\tilde{y}}_{21}}\right)\left(\frac{\pi^{11}}{\pi^{21}}\right)^{1 / \varepsilon} \geq\left(\frac{\overline{\tilde{y}}_{1}}{\overline{\tilde{y}}_{2}}\right)^{\frac{\gamma}{\varepsilon}}
$$

where $\overline{\tilde{y}}_{2}>\overline{\tilde{\tilde{y}}}_{1}$ by condition (iii). Also, by condition (ii) the left-hand side is lower than one, whereas by condition (iv) the left-hand side is greater than one. This proves that $\frac{\partial V}{\partial \delta_{11}}>0$.

G) Proof of Proposition 3.4. $h$-type positive dependence implies $\tilde{y}_{11}<\tilde{y}_{21}$ and $\tilde{y}_{12}<\tilde{y}_{22}$. By $e$-type positive dependence it must be the case that $\tilde{\tilde{y}}_{11}<\tilde{y}_{12}$ and $\tilde{\tilde{y}}_{21}<\tilde{\tilde{y}}_{22}$. All together, given $\pi^{2 \mid 2} \geq \pi^{2 \mid 1}$, it must be the case that $\overline{\tilde{\tilde{y}}}_{1}<\overline{\tilde{\tilde{y}}}_{2}$. As social welfare is defined as a power mean of $\overline{\tilde{y}}_{1}$ and $\overline{\tilde{y}}_{2}$, for $\gamma \rightarrow+\infty$ the Rawlsian result holds by which $V=\overline{\tilde{\tilde{y}}}_{1}$. Thus, any income switching benefitting the better $h$-type and penalizing the worse $h$-type must be socially undesirable.

\section{Copyrights}

Copyright for this article is retained by the author(s), with first publication rights granted to the journal.

This is an open-access article distributed under the terms and conditions of the Creative Commons Attribution license (http://creativecommons.org/licenses/by/4.0/). 